FABULARIO 



\title{
Estrategias del miedo al negro
}

\author{
Por Víctor Fowler ${ }^{1}$ \\ Instituto Dulce María Loynaz (Cuba)
}

Cuando en 1924 publicara Jorge Mañach la narración titulada "Belén, el aschanti", una de las pocas obras de ficción salidas de su pluma, colocó la contradicción en una dimensión diferente y aún más atractiva. La historia, ubicada en tiempos de la esclavitud, narra la trágica y turbia relación entre un esclavo negro de la dotación y la hija del dueño del ingenio azucarero. Si mucho es lo que Mañach desaprovecha del poderoso eje dramático que maneja, igual son abundantes las sugerencias en lo que nos queda: la desmesurada, inexplicada y rara atracción que se verifica entre los personajes que articulan la tragedia: el esclavo Belén y la Niña Cuca. En cuanto a la relación entre ambos, nada existe en el relato que permita suponer que fuese alguna vez más allá de simples gestos y ofrecimientos corteses de parte del esclavo. Y en cuanto a la Niña Cuca, ella siempre aparece investida de la autoridad que le confieren el color de su piel y su jerarquía social: es a Belén a quien vemos dirigírsele y a ella a quien vemos despreciarlo. En una relación tan por entero vertical, hemos de suponer que se interrelacionan por los estereotipos de inalcanzabilidad que ambos mutuamente representan: lo abyecto y lo sublime.

Puesto que el relato fue escrito en 1918, durante los tiempos de estudio del autor en la Universidad de Harvard, aún no habían pasado dos décadas desde la convulsión provocada en el país por varios escándalos que relacionaban "la brujería de los negros" con el secuestro, asesinato y sacrificio de niñas blancas y poco después por otra ola de odio racial durante el "alzamiento" de los Independientes de Color. A propósito de lo último es pertinente recordar que una de las consignas movilizadoras, insidiosamente deslizada en los medios de prensa, fue que los negros estaban violando a las mujeres blancas de la zona oriental y ya se sabe que miles de voluntarios se ofrecieron y fueron a reprimir a los "alzados", en un baño de sangre que culminó con más de 3000 asesinatos en solo unos días. Hablamos de hechos que resulta imposible mantener separados del breve relato de Mañach, intelectual blanco y poseedor de una de las inteligencias más brillantes del período republicano cubano;

\footnotetext{
${ }^{1}$ Poeta y crítico literario cubano. Ha publicado los libros Historias del cuerpo (2001); La maldición: una historia del placer como conquista (1998) y Rupturas y Homenajes (La 1999). Ganador del Premio Luis Rogelio Nogueras. e-mail: oppianos@gmail.com
} 
sobre todo, porque debió de tener absoluta conciencia de que con su historia trastornaba la comodidad del esquema donde el negro debe ser acorralado y extirpado. Los polos de la complejización son varios, pues la conexión se da entre adulto y adolescente, negro y blanca, incultura y educación, esclavitud y riqueza, fuerza y fragilidad. La conexión establecida durante los ataques histéricos de la niña, reverso patológico de una atracción sexual escasamente velada por el autor, culmina en tragedia cuando los perros de la casa, en el patio de la casa, destrozan a Belén, que al parecer se dirige a la ventana de Cuca. Es en este momento que el relato da un giro y quien con sus temores provoca la tragedia, la misma Niña Cuca, es quien solo llora la muerte de Belén, sino que ahí y en adelante se comporta como si padeciese el dolor de un amante perdido.

Semejante capacidad de lo abyecto para atrapar en su órbita al dominador, podemos interpretarla como una tensión e imaginar que nos dice algo sobre las dos razas principales que se funden en la nación cubana. Cierto es que, en el texto, el intento de salida se produce al precio de la muerte de ambos protagonistas, pero si no podemos aceptar como solución la desaparición física de las entidades simbólicas (de las razas blanca y negra, a fin de cuentas), ¿qué otra significación residual nos queda cuando concluimos la lectura que no sea imaginar que los sujetos mueren, aunque no la tensión?

\section{Desandando el esquema de Mañach}

En fecha reciente el esquema de Mañach ha sido objeto de revisión profunda en el cuento "Delfín de Eleguá", del narrador Eliseo Altunaga, perteneciente al volumen Todo mezclado. En esta ocasión el espacio de la plantación azucarera se brinda como escenario para los hechos y el contexto del Caribe como su telón de fondo. Esto último es fundamental para comprender las intenciones del autor, pues en sus historias de violencia y rebelión pretende revelarnos lo que se encuentra en el origen de nuestra historia; es decir, cómo hemos sido constituidos, cuáles fuerzas se movilizaron para ello, qué tenemos en común los países de esta parte del mundo y, esto último ocupando el lugar de súper objetivo en su discurso sobre la Historia, devolvernos la imagen de un universo donde las jerarquías aparentes se subordinan a la rigidez de las leyes económicas. Esto es claramente visible en la novela Canto de gemido, donde el personaje principal, Félix, mulato que fuera esclavo en Cuba y devenido pirata en las aguas del Caribe, ayudante del capitán André de la Coté, habita un universo cuyas articulaciones desconoce, abrumado sin descanso por la pregunta sobre el sentido: ¿quién soy? ¿cuál es mi lugar entre 
las cosas? Todo esto pudiera ser leído como un recorrido iniciático, pues le veremos ascender hasta la condición de capitán de piratas, respetado por unos y temido por otros, dueño de una libertad tan ancha como la Naturaleza en que se mueve; y esto para terminar descubriendo que es una pequeña pieza en los escalones de la dominación, que su destino es dictado por poderes innominados e impenetrables: las "Compañías", emporio del comercio asentado en Europa y que organiza la vida según una ética que él no sabe manejar. Quien primero lo comprende, antes que Féliz, es su capitán, André de la Coté, personaje de la nobleza de Francia quien, al irse al Caribe, huye a la vez de su pasado y condición, y por su mente se cruzan estas palabras cuando definitivamente se niega a seguir practicando la piratería: "El mar de las islas era solo otra dimensión de la enorme celda en que agonizaban. En el mar, seductor e inalcanzable, el tiempo era otro, pero al fin y al cabo, un tiempo, un límite, una contención. La historia estaba en todas partes..." (170) Antes de ello, hemos presenciado, en varias ocasiones, los momentos en los que André perdió la oportunidad de incorporarse al cambio que hace de él, blanco y antiguo aristócrata, un inadaptado de la Historia, un condenado. En tal sentido la narrativa de Altunaga es portadora de una densidad histórica de la cual carecen la mayoría de los textos que abordan el universo interracial: no solo André, que se siente quebrado en el momento mayor de su gloria, sino los "cientos de blancos pobres que había en el Puerto" (154) cuando los piratas arriban a Barbados, gente arruinada cuando la plantación azucarera desplaza el cultivo del tabaco en pequeñas granjas. De ahí que valga la pena contraponer un cuento como "Faraón del Nuevo Mundo" (perteneciente a Todo mezclado) a este reciente Canto de gemido; en el primer el capitán de un negrero se piensa a sí mismo del modo que sigue: "Traslado de brazos para nutrir a la insaciable Europa. Para hacer posible el azúcar, el café, el algodón. Todo por la fuerza, la voluntad y el ojo del capitán" (19), en tanto que el Segundo devela y se coloca en el extreme de esta mentida libertad cuando André descubre, mientras ataca Ciudad de Panamá al lado del mítico Morgan, que no es sino un peón más en manos de las lejanas Compañías. Tiempos antes, cuando todavía André era el capitán, Félix había escuchado el siguiente fragmento de conversación: "Los negocios rigen al mundo y oponerse a los negocios es salir del mundo", pero entonces había pensado que "eran palabras de ciudad, de voces lejanas y ocultas" (154) Tanto el capitán del cuento como el pirata de la novela son oposiciones al paradigma de tranquilidad de burgueses y aristócratas europeos; son fugas del orden, ambas inevitables, a las que unifica idéntica carga de suciedad y rechazo. Encarnan una magnitud de violencia y caos irreductible a la vida del salón, la corte o la oficina del banquero, de todos quienes son un 
sangriento reverso. En voz del capitán: "Sirviendo a una civilización que me desprecia, a un mundo que me necesita y pretende ocultarme como a un hijo marchito." (7) Algo parecido sacudirá a Félix de la Coté con la violencia de una revelación en Panamá; corre hasta Morgan para evitar la segura guillotina y el estallido de ira sobre la ciudad derrotada: "Déjalos un poco. Félix, después de esto, los españoles tendrán que comerciar" (187), responde el inglés y es entonces que se abren los velos de su destino: no es más que una pieza y su rabia, cuando toma una tea para destruir, un río que engrosa el torrente de ansias manejado por las Compañías.

Precisar la voluntad de inscribirse en un discurso de la caribeñidad que recorre el texto de Altunaga es vital para acercarnos a "Delfín de Eleguá", relato perteneciente al volumen Todo mezclado cuya acción tiene lugar en Cuba. En esta ocasión el escenario es un ingenio azucarero $\mathrm{y}$, en principio la estructura repite elementos del esquema Mañach: Mariana el alma blanca, utiliza a Delfín como esclavo personal, negro fuerte cuya figura hace que el amo lo piense más apto para las labores del campo que par a las faenas domésticas; también aquí el esclavo se desvive por proteger al alma, pero los lazos entre los personajes son mucho más complicados y los mismo su comportamiento. Para comenzar la primera mención a Delfín, hecha por el amo, es para avisarnos que se ha fugado, cosa que indica la rebeldía frente a su condición; además de ello, aparece aquí el personaje de Irma, negra que administra la casa y a la que el amo ha tomado como amante. Lo segundo que sabemos sobre Delfín es nuevamente un comentario indirecto, ahora cuando mediante la posición omnipresente del narrador nos es dado el acceso al castigo que sufrió luego de la captura: “...el bocabajo, las huellas de los latigazos, la risa de los mayorales y contramayorales" (49), y, después de ello, el trabajo en los cortes de caña con las heridas abiertas. La conjunción del castigo con la risa del dominador, imagen común en la narrativa antiesclavista, cambia por entero a Delfín y el relato da un giro hacia la organización de una revuelta. A partir de aquí los motivos eróticos se entrecruzan con el temblor soterrado de la revuelta, pues Mariana, que ha estado leyendo a Santa Teresa, acaricia la daga que Delfín usa para protegerla cuando se le ocurre a ella salir a pasear por el monte; la connotación fálica del instrumento es por entero transparente: "vuelve a acariciar la funda que se le antoja de la misma textura que la tiznada piel del esclavo". (50) Y es que la lectura de Santa Teresa resulta ser, no por coincidencia aquel capítulo que conocemos como "La Reverberación"; es decir, cuando la religiosa interpreta el conocimiento de Dios bajo la figura de un querubín armado de un ardiente dardo de oro y hierro que le atraviesa el corazón y vacía las entrañas. Para colofón de la escena 
nos queda la entrada de Delfín: viene cubierto con "el sombrero del amo, fuma uno de sus tabacos y le hace un simpático gesto con los brazos cruzados por las muñecas, subiéndolos y bajando en dirección al pubis, como el travieso de Eleguá". (52) Estamos al borde de que la sexualidad interracial se consume, pues la excitación del ama y el obsceno gesto del esclavo son signos inequívocos; sin embargo, es justo el signo lo que nos confunde, pues ¿cómo explicarnos que este esclavo escapa del barracón y que viste la ropa del amo? Delfín acaricia el cuerpo desnudo de su ama, pero será para terminar hundiéndole la daga en el cuello, pues no otra cosa que la rebelión es lo que se consuma y cierra un arco que nos aleja definitivamente de la romantización interesada de Mañach.

\section{Bibliografía}

Altunaga, Eliseo. (1984). "Delfín de Elegúa”. En Todo mezclado. Editorial Letras Cubanas: La Habana.

Altunaga, Eliseo. (1988). Canto de gemido. La Habana: Letras Cubanas. Mañach, Jorge. (1924). Belên, el Aschanti. S/D. 
